\title{
O USO DA CRONOANÁlise PARA A CLASSIFICAÇÃo E MEDIÇÃo DE DESPERDÍCIOS EM UMA MULTINACIONAL DO SETOR ELETRÔNICO
}

\author{
Andreza Aparecida da Silva ${ }^{1}$ \\ Gabriella Aparecida Ferraz Albino ${ }^{2}$ \\ Dalton Garcia Borges de Souza ${ }^{3}$
}

Resumo: O Lean Manufacturing é uma metodologia comumente empregada e indispensável às organizações que buscam empoderar seus resultados, pois aumenta a capacidade de criação de valor ao cliente ao permitir maior flexibilidade e agilidade do processo produtivo. O presente estudo de caso descreve o método utilizado para mensurar os desperdícios que afetam a performance de uma multinacional do setor eletrônico. Com base nos dados coletados através da cronoanálise, geraram-se gráficos que apontaram o percentual de perda, possibilitando classificar os desperdícios capazes de impactar negativamente toda a cadeia de valor.

Palavras-chave: Lean Manufacturing; Cronoanálise; Mensuração; Desperdícios.

\footnotetext{
1 Graduanda em Engenharia de Produção/FEPI - Centro Universitário de Itajubá, Brasil. E-mail: andrezasilvap@hotmail.com.

2 Graduanda em Engenharia de Produção/FEPI - Centro Universitário de Itajubá, Brasil. E-mail: gabriellaferraz52@yahoo.com.br.

3 Mestre em Engenharia de Produção/FEPI - Centro Universitário de Itajubá, Brasil. E-mail: souza.dgb@outlook.com.
} 